\title{
Ana Gallego Cuiñas, Las novelas argentinas del siglo 21. Nuevos modos de producción, circulación y recepción. New York, Peter Lang, 2018, 160 páginas
}

\author{
Munir Hachemi Guerrero
}

Cita sugerida: Hachemi Guerrero, M. (2020).

[Revisión del libro Las novelas argentinas del siglo 21. Nuevos modos de producción, circulación y recepción por A. Gallego Cuiñas]. Orbis Tertius, 25(32), e180. https://doi.org/10.24215/18517811e180

"Hablar de dinero es para nosotros, ciudadanos de una sociedad capitalista ultraliberal, un tabú". La cita es de un artículo de la autora del libro que reseñamos, Ana Gallego Cuiñas. Si la literatura —sea lo que sea eso, y concretamente la novela, que es el género que ocupa a la investigadora en este libro- "habla de" y la crítica, añadiendo un grado de mediación, "habla de lo que habla de" resulta casi milagroso que en Las novelas argentinas del siglo 21 Gallego Cuiñas rompa el tabú y hable, sobre todo, de dinero (vale decir: de valor y de la materialidad de lo literario).

La autora comienza así, situándose con una actitud hiperconsciente que mantendrá durante todo el volumen. Argentinista que escribe desde este lado del Atlántico (x), feminista (xiii), de izquierdas y que "parte de la idea de que la literatura es un producto ideológico" (xii), Gallego Cuiñas tiene a sus espaldas una prolífica producción según la que concibe la literatura desde la categoría central de lo material (sin olvidar, como señala Althusser y recuerda la autora, que "todo es material"). Además de todo lo anterior, Gallego subraya de la importancia del arranque, del incipit, y por eso lo utiliza para situarse en el campo de la crítica académica.

El libro está dividido en partes que podrían funcionar de forma autónoma pero que se entrelazan para dar una perspectiva amplia, aunque no totalizadora (xi) de las novelas argentinas del siglo 21 (la autora evita escribir "XXI" para "evidenciar que lo nuevo de este siglo reside en su carácter material y económico").

El capítulo primero, "Claves para pensar las literaturas del siglo 21" funciona como recapitulación del corpus teórico que la autora ha utilizado en anteriores trabajos al tiempo que como construcción del lugar desde el que se leerán las novelas que son objeto de estudio en el libro. Comienza por desgranar profusamente la tradición teórica en la que se ubica: Lukács, Benjamin, Adorno, Barthes, Bajtín, Rancière, para continuar 
justificando el motivo que la ha llevado a escoger la novela como objeto de análisis. Es "el género burgués por excelencia" en el que se condensan los complejos haces de relaciones que vertebran el capitalismo. Desde su perspectiva materialista, Gallego Cuiñas nos descubre los lugares de poder en torno a los que forja su mirada. El primero es la figura del escritor (no "autor") hoy profesionalizada y llevada al extremo en tanto performance inacabable de una subjetividad en constante exposición. El siguiente, central en todo su pensamiento de los últimos años, es el de la oposición entre los grandes conglomerados y las editoriales independientes, que se exacerba en la Argentina a partir de la crisis de 2001. En su indagación en busca de los dispositivos de producción del valor, Gallego Cuiñas también señala los festivales, las ferias, la caída de la Historia y la proliferación de las historias proveniente del efecto de verdad del género testimonial que estuvo en auge en los ochenta y los noventa, el feminismo y, más en general, el género, la categoría de lo nuevo y en especial el interesantísimo concepto de gatekeeper para analizar la relación entre el campo español y el argentino. Como se puede notar en la enumeración anterior, Gallego cumple la máxima althusseriana y navega con comodidad a un lado y otro de la dicotomía que separaba tradicionalmente la base material y la superestructura ideológica, y no lo hace por azar sino sirviéndose del complejo concepto de dispositivo, aquí en su acepción foucaultiana pero que - como demostró Agamben — proviene de Hegel — Hyppolite mediante- y que fue revisado más tarde por Deleuze.

En el segundo capítulo, "Comienzos de la novela argentina actual”, la autora justifica la elección de las obras sobre las que trabajará: sólo primeras novelas. Lo hace bajo la premisa de que es en este tipo de textos donde los escritores se ubican de forma más clara frente a los problemas de su campo nacional, donde se ve con más nitidez el lugar desde el que quieren ser leídos. A continuación Gallego Cuiñas traza esas coordenadas. En primer lugar, el posicionamiento frente a las grandes figuras tutelares: Piglia, Saer, Aira, Borges, sobre todo, pero también Fogwill, Cortázar, Libertella, etcétera. Desgrana otras oposiciones, problemas que vertebran el campo y dese los que nos es posible plantear una mirada cartográfica: las representaciones de la violencia, el lenguaje, la frontera, los medios de masas, la comunidad, la edición independiente, el testimonio, la multiplicidad de medios (documentos, imágenes, etcétera), la cuestión de lo nacional o lo posnacional, la importancia de la academia y la figura del escritor-profesor, la relación con el mercado, el auge de los géneros de mayor densidad biográfica, la literatura mundial, el feminismo, el género, el cuerpo.

$\mathrm{Al}$ tiempo que Gallego Cuiñas traza su rosa de los vientos nos comunica los textos que componen su corpus (p. 27). Dada la naturaleza de esta reseña y la longitud de dicho corpus no nos parece pertinente reproducirlo, pero baste mencionar la gran presencia de mujeres (García Lao, Cabezón Cámara, Romina Paula, Oloixarac, Almada, Harwicz...), de autores jóvenes (Bruzzone, Havilio, Larraquy...) y la importancia que la autora concede a antologías seminales como La joven guardia de Maximiliano Tomas, Una terraza propia de Florencia Abbate y varias más, así como a la prensa, los suplementos culturales y, por supuesto, los talleres y los cursos de escritura creativa.

Para la autora la cuestión de género atraviesa toda la nueva narrativa argentina. Es por eso que divide los dos capítulos que siguen: por un lado la mayor parte de las coordenadas, por otro las relacionadas con el feminismo. Así, el capítulo tres, "Mediadores de la literatura argentina mundial", estudia los modos de transferencia del campo argentino al campo mundial. Inicia con un estudio minucioso del panorama editorial argentino para concluir que las independientes funcionan en muchas ocasiones como cantera de los grandes conglomerados, que son condición de acceso a la mundialización. Una de las afirmaciones más interesantes del capítulo es aquella en la que propone que Anagrama ha sido sustituida (o está en proceso de serlo) como gran gatekeeper de la literatura latinoamericana por Eterna Cadencia. En su análisis pormenorizado la autora recorre los catálogos de ambas y constata una clara disminución de la presencia latinoamericana en la española, que ahora optaría más bien por una literatura à la anglosajona, de trama sencilla y exportable, más fácil de traducir y mundializar. La tendencia que Gallego Cuiñas señala constituye también un estadio del proceso descolonizador que ella misma señala y en el que podemos ubicar las políticas proteccionistas del libro que caracterizaron los mandatos de Cristina Fernández de Kirchner e incluso la sonada nacionalización 
de YPF. De nuevo, el libro mantiene una perspectiva materialista y ahonda en los dispositivos, en las correas de transmisión que desembocan en la producción literaria.

Otro de los centros de su análisis es el de los talleres literarios, que han sido poco estudiados hasta la fecha. Gallego señala la convergencia entre una desmitificación de la figura del autor hacia la del escritor y el auge de estas formas de transmisión del "oficio literario". En un pasaje especialmente lúcido, escribe:

Lo descrito pone en evidencia, en primer lugar, la prístina y problemática relación entre literatura y trabajo, que el sistema universitario americano, capitalista y positivista, resuelve - por fin - con la venta de titulaciones centradas en la labor técnica y material del escritor, que tradicionalmente se había resistido a una formulación exacta (recordemos el célebre Poet nascitur non fit) (p. 80).

Si la concepción de la literatura como oficio transmisible es señalada como un síntoma del avance del capitalismo, eso no significa que desde los espacios que produce ese avance no se pueda articular alguna forma de resistencia. Del mismo modo en que los talleres artesanales fueron en el siglo XIX un centro de lucha contra el avance de formas de trabajo netamente capitalistas, de la composición de la fuerza de trabajo en busca de la optimización del plusvalor, los talleres literarios conforman lugares en los que pueden darse formas resistentes de comunitarismo, relaciones con un estatuto diferente al de lo social, aunque terminen por abrirse a esa segunda categoría. La comunidad en los talleres es condición de posibilidad para la resistencia, pero no existe necesidad entre ambas instancias. En los grandes cursos o en las maestrías, sin embargo, Gallego detecta la asunción plena de formas de mercantilización y de mediación explícitamente orientadas al salto de los asistentes a la literatura mundial. Esa venta a futuro sí hace imposible cualquier forma de resistencia. Así, la autora sentencia que hoy día "el taller literario es a la editorial independiente como el máster de escritura creativa al gran conglomerado".

El último capítulo, "Novísimas escritoras argentinas" ahonda en la escritura de jóvenes autoras argentinas (Enríquez, Schweblin, Almada, Gainza, Harwicz...) y analiza los nuevos modos en que éstas trabajan las relaciones de opresión vinculadas con el género. Si en la anterior generación (con algunas excepciones) bastaba con cierta exhibición de la feminidad, Gallego señala que en ésta se ahonda en su problematización y se aborda la condición de mujer sin eludir su complejidad y, a veces, cargando frontalmente contra los roles con que se asociaba tradicionalmente o denunciando desde una literatura documental muy politizada las violaciones y los feminicidios. Si bien todo el análisis resulta de gran interés, quizá la aportación más original de la autora sea el descubrimiento (también en el sentido de desvelamiento) de lo que podríamos llamar un feminismo mundial, ciertos discursos feministas establecidos que lejos de suponer un obstáculo a la hora de acceder a los centros del poder institucionalizado pueden llegar a ser una condición de paso para la mundialización.

El libro cierra con un epílogo que recapitula las ideas expuestas y abre algunos caminos. En esta reseña hemos dejado sin comentar algunos aspectos del volumen (si hubiéramos procedido de otro modo habríamos acabado por incurrir en el error del problema de "El rigor en la ciencia", como la propia autora señala (xi)). Por ejemplo, cabe destacar la idea de que el rubro de lo nuevo y de la novedad editorial se ha convertido en una etiqueta que produce valor en el interior de un mercado del libro que se guía por un frenesí antes desconocido. También hemos omitido las particularidades del género novelístico, el más mutante, el que mejor se inserta en el mercado del libro neoliberal (p. 155).

Reconozcamos para terminar que no podemos agotar las aristas de la articulación entre los modos de la materialidad que propone Gallego Cuiñas. Para eso, en cualquier caso, tenemos su pensamiento, puesto en volumen en este libro. Cerraremos, eso sí, alegrándonos junto a ella de que estemos asistiendo a un nuevo "giro materialista" del que Las novelas argentinas del siglo 21 es un ejemplo privilegiado, y que cristaliza

en el debate en torno a la definición de lo literario hoy, al agotamiento de determinadas herramientas teóricas, a la necesidad de volver a la sociología de la literatura en el contexto neoliberal del siglo XXI (p. 155). 